\title{
Chapter 2 \\ Importance of Craniofacial \\ Superimposition in Forensic Identification: \\ Historical Perspective
}

The successful comparison of human skeletal remains with artistic or photographic replicas has been achieved many times using CFS. From the identification of wellknown criminals, such as Adolf Hitler's chief medical officer Dr. Josef Mengele (Teixeira 1985; Helmer 1987), to the identification of victims of the recent Indian Ocean tsunami (Al-Amad et al. 2006) and in the identification of terrorists (Indriati 2009), this technique has been under continued development since its first application in 1935 (Glaister and Brash 1937). Craniofacial superimposition has become increasingly relevant in forensic scenarios worldwide.

Case studies are ideal for providing information regarding the evolution of the CSF technique and its application in various forensic situations. The most relevant identification works based on CFS throughout history are reviewed below.

The first documented cases, in which ante-mortem images were compared to cranial remains, date to the early twentieth century. In these instances, CFS served as supporting evidence to be presented in court rather than the principal means of identification of the victim.

Perhaps the most prominent case of this early period is the Ruxton case in 1937, in which two female skulls were compared to photographs of missing women using the superimposition technique (Glaister and Brash 1937). The comparison served as supporting evidence in the identification of the two skulls. However, the CFS evidence was not accepted by the court as a means for confirming a positive identification.

After Ruxton, the second case recorded in the literature is the Baptist Church Cellar Murder. In this case, the Photography Department of Guy's Hospital in London was able to superimpose a full-face portrait of a woman onto a full-face X-ray of a skull. The resulting superimposition contributed to the identification of the woman (Simpson 1943).

Three years later, Gordon conducted the identification of a severely burnt body found in an incinerated car near Durban, South Africa. Once again, based on the methodology followed in the Ruxton case, the investigators obtained three photographs of the suspected victim in order to make a comparison with the skull. The 
photographs were used to draw an outline of the head of the victim, which was superimposed onto a machine-made projection drawing of the skull in approximately the same orientation as the head in the photograph. Based on good anatomical correspondence, the investigators established the identification with a considerable degree of probability (Gordon and Drennan 1948).

Other cases in which photographic superimposition was accepted as part of the evidence for identification have been reported in South Africa, (Prinsloo 1953) and Sri Lanka. The latter case, known as the Plumbago Pit case in 1947, aroused public interest, when a putrefied body was found floating in a pit. One and a half months later, without solid evidence as to the identity of the body, Professor G. S. W. Saram explored the possibility of applying the CFS technique. Once again, the methodology was based on the Ruxton case. Neither the identity of the body nor the accuracy of the technique employed was questioned during the trial (Webster 1955).

Although the CFS technique has proved to be helpful in the identification process, the first positive identification accepted in court, based solely on CFS, took place in 1962 in a case reported by Sen (1962). Sen's paper does not offer many details on the methodology implemented, but it does mention that the investigators performed control experiments on collections from the Anatomy Department of the Calcutta Medical College to validate their findings. The Supreme Court of India accepted the comparison of the photo and the skull as evidence for a positive identification (Ubelaker et al. 1992).

In 1973, a prominent case was reported in India. Dismembered parts of a human body, including a human skull, were found over a period of 5 days and an analysis was conducted in order to obtain a positive identification. Captain K. Nagaraju, a doctor in the Indian army, was suspected of murdering his wife and child on a train during their journey from Delhi to Secunderabad. In a hotel bathroom in Secunderabad, he dismembered his wife's body into portions convenient for transport and dumped them at various places in a nearby tank to cover up the crime. The skull was identified by superimposing its photograph over a negative of an ante-mortem photograph of the suspected victim using the negative placed under the ground glass of the camera and marking the salient features of the face on the glass. The skull was mounted on an appropriate skull rest, placed in front of the camera and positioned so as to align it as accurately as possible with the outlines on the ground glass, making due allowance for the soft tissues covering the bone. In this position, a negative of the skull was prepared. The negatives of the photograph and the skull were superimposed by aligning the characteristic points in the negatives. In the report, the following cranial and facial landmarks were noted: (1) the eyes within the orbital plates, with the two pairs of canthii properly aligned; (2) the nasion; (3) the prosthion in the central line; (4) the nasal spine in the centre, which is a little above the tip of the nose; (5) the lower border of the nose; (6) the lower border of the upper jaw, that is, below the tip of the nose; and (7) the zygomas below the eyes. This case resulted in a positive identification and with the suicide of Doctor Nagaraju (Reddy 1973).

One of the most famous identification cases resolved by the use of CFS is that of Dr. Josef Mengele in Sao Paulo, Brazil, in 1985, the infamous physician of the 
concentration camp in Auschwitz. Following a request made by the Brazilian authorities, a team of Brazilian, German, and American Scientists exhumed the remains of a cadaver suspected to belong to Dr. Josef Mengele, based on the information that he died in Brazil on February 7, 1979, and was buried in the cemetery of Embu/São Paulo. Comparative data for the identification of the skeleton was recovered from a medical examination sheet from the SS main office for Race and Settlement in 1938. Data collected included date of birth, height, weight, cranial circumference, cranial form, type of body structure, two photographs of Dr. Josef Mengele in frontal and lateral views at the age of 27 and three at the age of 60. The authors concluded, based on various techniques, including CFS, that "there is no room for doubt that the exhumed skeletal parts are the remains of the corpse of Doctor Joseph Mengele" (Helmer 1987).

Some years later, the presumed skull of W. A. Mozart was examined by a team of French scientists (Puech et al. 1989). The skull was measured exhaustively and it was found to have a very distinctive form (vertical forehead, reduced orbits, and alveolar prognathism). The cranium was superimposed onto wax portraits of Mozart, available from 1778 (The André Meyer collection) and from 1788 by L. Posch. The superimpositions showed good correspondence in the forehead contour, nasal profile, orbit shape, and cheek position. An analysis of the investigation indicated that there was complete conformity concerning all side proportions of the head. This "positive match" put an end to the stories about the remains of Mozart being lost among the mixed bones of St. Marx's cemetery in Vienna (Helmer et al. 1989).

The first 50 years of development of the CFS technique is defined largely by case reports (Sen 1962; Reddy 1973; McKenna et al. 1984; Bastiaan et al. 1986; Basauri 1967; Vogel 1968; Sekharan 1971; Gejvall 1974; Sivaram and Wadhera 1975; Janssens et al. 1978; Brown 1982; Webster et al. 1986). These identification cases, solved using only photographs of both the skull and the face, belong to the first generation of CFS methods called photographic CFS. In the ensuing years, a new modality of CFS techniques based on video technology made their way into the scientific realm. Helmer and Grüner (1977a, b) were the first researchers to introduce the video superimposition technique. They took advantage of the "live images" of the object (skull and photograph) instead of taking photographs, or making tracings or drawings of the skull and face to superimpose them. These systems present an enormous advantage over the former photographic superimposition technique (Helmer and Grüner 1977a; Shahrom et al. 1996; McKenna et al. 1984; AustinSmith and Maples 1994; Yoshino et al. 1995; Solla and Iscan 2001; Fenton et al. 2008) and video superimposition is probably the most broadly employed method in terms of the number of cases solved to date.

One of the first reports in the literature, regarding the use of CFS in a mass casualty incident, belongs to the video CFS modality. In February 2003, commingled human bones were recovered from the Sonora desert in Arizona. Among the numerous human postcranial skeletal elements, five skulls were found (three females and two males). The presumed identity of the victims was known; thus, the incident was considered a closed disaster. The two male victims and the youngest of the three female victims were identified through the analysis of their 
biological profiles, conducted by a forensic anthropologist. The biological profiles of the final two females were very similar, requiring the use of other identification methods to discriminate between them. During the investigation, a photograph of one of the females was found and used to apply the CFS technique by a team of investigators from the Michigan State University Forensic Anthropology Laboratory. The use of the following equipment was reported for the implementation of the technique: two video cameras, a video mixer, a TV monitor, a video cassette recorder, and a desktop computer with image-capturing software. Through this analysis, the investigating team was able to exclude one skull and include the other skull as a possible match. During an in-depth analysis of the technique, the authors concluded that CFS should only be used to exclude or fail to exclude an individual as a potential match, rather than to explicitly identify cadaveric remains (Fenton et al. 2008).

Despite the high number of cases positively identified using video superimposition techniques, the popularization, dramatic development, and endless possibilities offered by computers have turned them into the next-generation CFS systems.

The first documented case of a superimposition performed using a "computerenhanced" method was developed by a team of experts from the FBI, led by Prof. Ubelaker, in 1992. In 1991, a cranium and a mandible discovered in 1978 by a hunter in Putnam County, Ohio, were forwarded to the FBI alongside a facial photograph of the presumed victim. The investigators compared the photograph of the presumed victim and the articulated cranium and mandible with the help of a personal computer and proclaimed this approach "a new, rapid and highly effective method to demonstrate consistency between skeletal features of the head and facial photographs" (Ubelaker et al. 1992). Another well-known computer-assisted CFS case involved the identification of Dr. Eugénio Antonio Berríos Sagredo, the physician accused of making nerve gas during the dictatorial regime of former Chilean President General Augusto Pinochet and whose remains were found in Uruguay in 1995 (Solla and Iscan 2001).

A variety of software packages are used to perform CFS, the most common one is Adobe Photoshop ${ }^{\mathrm{TM}}$. Bilge et al. (2003) described their use of this software together with Corel Draw ${ }^{\mathrm{TM}}$ in order to identify a decapitated body found in a suburban area of Ankara (Turkey). Cadaveric remains were found buried nearby an area where a skull exhibiting two gunshot wounds was found. In order to determine if the skull could be associated to the decapitated body, which had been identified by the wife of the deceased, the authors superimposed a photograph of the victim onto the disassociated skull and reported an "excellent adaptation." The positive match achieved by CFS was confirmed by a DNA analysis performed on the bones, dental pulp, and muscle tissue of the victim (Bilge et al. 2003).

As expected, CFS systems based on the use of computers have become consistently more popular among practitioners. The final example of the use of such a system was recently reported by Pushparani et al. (2012). In this case, an approximately 25 -year-old male skeleton was found with a photograph next to it. The photo and the cranium were examined by the Anthropology Division of the Forensic Sciences Department in India. They employed computer-aided video 
superimposition to perform a match between the photo and the cranium, concluding a likely identification. This was later confirmed by the radiographic comparison of a surgical plate found on the femur of the skeleton and the corresponding ante-mortem plate collected by the authorities (Pushparani et al. 2012).

Furthermore, in the last 5-10 years, the superimposition technique has been greatly simplified by automating the overlay process through computer-aided methods (Nickerson et al. 1991; Ghosh and Sinha 2001; Ibáñez et al. 2009a). These are proposed to be the next-generation CFS systems. However, their use in identification cases is still very limited. Only one case has been reported in the literature that makes use of the Ghosh and Sinha (2001) CFS identification system (Ghosh and Sinha 2005). In this instance, an unidentified skeleton was found in a bush. The remains were photographed in situ and then collected by the authorities. As the body was never claimed, following the post-mortem examination, the skeleton was cremated as is customary in India. A month later, the police found new evidence in the identification of the remains, but as they were no longer available, the investigators employed a novel CFS technique involving the preprocessing of the images from the scene for subsequent analysis by using artificial intelligence techniques. The proposed algorithm compared frontal views of the cranial and facial images and analyzed their hidden symmetry. During this process, the robust system suitably takes care of any ambiguities caused by soft tissue thickness in facial feature selection. The authors successfully superimposed one of the photos taken by the authorities onto one of the ante-mortem photographs of the deceased individual, achieving a positive match between the two pictures (Ghosh and Sinha 2005).

This last case is, most probably, the forerunner of the next-generation CFS techniques. As the steps for achieving the superimposition itself are simplified by the use of computer techniques, this forensic method of identification will gain more acceptance among the scientific community.

Open Access This chapter is licensed under the terms of the Creative Commons AttributionNonCommercial 2.5 International License (http://creativecommons.org/licenses/by-nc/2.5/), which permits any noncommercial use, sharing, adaptation, distribution and reproduction in any medium or format, as long as you give appropriate credit to the original author(s) and the source, provide a link to the Creative Commons license and indicate if changes were made.

The images or other third party material in this chapter are included in the chapter's Creative Commons license, unless indicated otherwise in a credit line to the material. If material is not included in the chapter's Creative Commons license and your intended use is not permitted by statutory regulation or exceeds the permitted use, you will need to obtain permission directly from the copyright holder. 